\title{
Syllables and spelling units affect feature integration in words
}

\author{
MICHELLE L. MILLIS \\ New College of the University of South Florida, Sarasota, Florida
}

\begin{abstract}
Three experiments showed that syllables and spelling patterns function as higher order units in word perception. Subjects were required to identify the color of a target letter in briefly presented words composed of different-colored letters. In Experiment 1, subjects incorrectly reported the color of a nontarget letter (conjunction error) more often in one-syllable words containing few spelling units than in two-syllable words containing many spelling units. Experiment 2 showed that subjects made more conjunction errors in one-syllable words than in two-syllable words when the number of spelling patterns was controlled. Experiment 3 showed that conjunction errors decreased as spelling units increased when the number of syllables was held constant. Experiments 1 and 3 also showed that more conjunction errors occurred within syllabic and spelling units than between these units. These findings are discussed in light of previous research on syllable and spelling pattern effects.
\end{abstract}

Several theories of visual pattern recognition propose that feature information is extracted when a particular pattern is presented (Bjork \& Murray, 1977; Estes, 1972; Rumelhart, 1970; Shiffrin \& Geisler, 1973). This information is then compared with feature groups stored in memory that represent each potential pattern that may have been shown. A correct identification results when sufficient feature information has been extracted to distinguish the presented pattern from other potential patterns. Errors occur in pattern recognition when the critical features necessary to distinguish between patterns are unavailable. The failure to extract enough feature information to correctly identify a pattern will be referred to as a feature error.

Although these feature-analytic theories are able to account for the recognition of isolated patterns, most do not adequately explain the recognition of several patterns presented simultaneously. These theories fail to specify the mechanisms by which features extracted from simultaneously presented patterns are appropriately parsed into groups before they are compared with feature groups in memory. Several researchers have attempted to resolve this problem by developing theories that specify the way in which features are combined into groups (Prinzmetal, 1981; Treisman \& Gelade, 1980; Treisman \& Schmidt, 1982; Wolford, 1975; Wolford \& Shum, 1980). These theories suggest that errors may occur in pattern recognition because features that are correctly extracted from several patterns are incorrectly combined.

Treisman and Gelade (1980), for example, proposed a theory that specifies the way in which features are integrated to form complex objects. They postulated that, in a preliminary stage of perceptual processing, features are extracted in parallel from stimulus displays. Focused

Reprint requests should be sent to the author at: Department of Psy chology, Santa Clara University, Santa Clara, CA 95053. attention is then directed serially to the features extracted from each stimulus location, allowing these features to be correctly recombined into unitary objects. When features from two or more objects fall either within or outside the focus of attention, these features are combined randomly. Thus, some errors occur in pattern recognition because correctly extracted features are incorrectly combined. Treisman and Gelade referred to the inappropriate integration of features as a conjunction error.

Treisman and Schmidt (1982), using different-colored letters as stimuli, attempted to demonstrate that conjunction errors occur in a variety of experimental tasks. They found that subjects sometimes reported correctly identified colors and letters in incorrect combinations. For example, when briefly shown a red $\mathrm{N}$, a green $\mathrm{X}$, and a blue $S$, subjects sometimes reported seeing a red $X$. Treisman and Schmidt recognized that some of the errors recorded as conjunction errors may have occurred because letters and colors were misperceived (feature errors) rather than miscombined. For example, subjects may have failed to extract the color of the $\mathrm{X}$ and simply guessed that it was red. However, because subjects made significantly more conjunction errors than were expected by chance, Treisman and Schmidt concluded that some of the conjunction errors must have represented inappropriate combinations of correctly extracted features.

Prinzmetal (1981) demonstrated that conjunction errors are affected by some of the Gestalt principles of perceptual organization. He presented subjects with rows of circles containing vertical and horizontal diameters as well as pluses. The subjects' task was to respond "yes" or "no" depending on whether a plus appeared in the display. Prinzmetal found that subjects often inappropriately combined the vertical and horizontal diameters into "illusory" pluses. In addition, these conjunction errors occurred more often when the target lines belonged to circles in the same Gestalt perceptual unit than when they 
belonged to separate perceptual units. These results suggest that features belonging to different perceptual units are constrained from combining with one another, whereas features belonging to the same perceptual unit are free to miscombine.

The finding that feature integration is influenced by perceptual unit boundaries suggests that conjunction errors may be used to study the perception of words. Several theories propose that groups of letters serve as higher order units in word perception. This explanation has been termed the unitization model by Smith and Haviland (1972). Prinzmetal and Millis-Wright (1984) tested this model by requiring subjects to identify a colored target letter in words and nonword letter strings composed of different-colored letters. The claim that word processing involves multiletter units suggests that when words are shown in this type of experiment, the colored target letter should be processed as part of a larger perceptual unit that also contains information about nontarget letters and colors. When a nonword letter string is presented, however, each of the colored letters should be processed as a separate perceptual unit. Prinzmetal's (1981) finding that features within a perceptual unit are more likely to miscombine than are features belonging to different perceptual units leads to the prediction that subjects should incorrectly integrate letters and colors more often when presented with words than when presented with nonwords. The results of Prinzmetal and Millis-Wright's (1984) experiments supported this prediction. This finding suggests that multiletter units are processed in words, whereas only individual letters are processed in nonwords.

Other experimental paradigms have also been used to provide evidence for the unitization model. These experiments demonstrate that letters are identified more accurately in words than in nonwords. In the whole report method, for example, subjects are presented with words and nonwords for a brief exposure duration. The subjects' task is to report all of the letters they can see. The typical finding is that more letters can be identified when the letters form words than when the letters are ordered randomly (e.g., Cattell, 1886). In a detection or forced-choice procedure, words and nonwords are also presented for a brief exposure duration. However, in this type of experiment, subjects are usually required to determine which of a set of possible target letters appeared in the letter string. The typical finding is that target letters are identified more accurately in words than in nonwords (e.g., Reicher, 1969). This word advantage in letter recognition is known as the word superiority effect. A third paradigm also presents words and nonwords for a brief exposure duration. However, in this type of experiment, the initial exposure duration is too brief for subjects to detect anything. The exposure duration is increased by a set amount of time, and the letter string is presented again and again, until subjects are able to correctly identify all of the letters in the stimulus string. The typical finding is that the report threshold for words is lower than the report threshold for nonwords (e.g., Gibson, Bishop, Schiff, \& Smith, 1964; Pillsbury, 1897). According to the unitization model, words are perceived "better" than nonwords in these experiments because there are fewer perceptual units to be processed.

What properties allow words to be processed as multiletter units? One property that distinguishes words from nonwords is that the component letters of words are related by spelling and pronunciation rules (Manelis, 1974). Only certain combinations of letters may occur in specific positions in words, whereas any combination of letters is permitted in nonwords. This structural property characterizes pronounceable pseudowords as well as words. Pseudowords are strings of letters that follow spelling and pronunciation rules but that have no meaning (e.g., GLURCK). Evidence that this property allows letter strings to be processed as higher order units comes from studies demonstrating that the word superiority effect generalizes to pseudowords. For example, several investigators have shown that letters in pseudowords are identified more accurately than are letters in unpronounceable/orthographically irregular nonwords (Aderman \& Smith, 1971; Baron \& Thurston, 1973; Carr, Davidson, \& Hawkins, 1978; Gibson, Pick, Osser, \& Hammond, 1962; Spoehr \& Smith, 1975). In addition, many studies have demonstrated that subjects' performance with words does not exceed their performance with pseudowords (Baron, 1974; Baron \& Thurston, 1973; Egeth \& Blecker, 1971; Gibson et al., 1962; Hermann \& McLaughlin, 1973; McClelland \& Johnston, 1977; Spoehr \& Smith, 1975). Prinzmetal and Millis-Wright (1984) also found converging evidence for this claim; they showed that subjects incorrectly combine colors and letters more often in pseudowords than in nonwords.

The findings of the above-mentioned experiments suggest that the multiletter units in word perception may be spelling units (Gibson, 1965) or phonological units, such as syllables (Spoehr \& Smith, 1973). The results cannot be used to distinguish between these multiletter units, however, because words and pseudowords are both more orthographically regular and more pronounceable than nonwords. The purpose of the present experiments was to use conjunction errors to determine whether either or both of these higher order units are processed in words. Subjects were required to identify the color of a target letter in briefly presented words composed of differentcolored letters. Experiment 1 compared conjunction errors in one-syllable words containing few spelling units and two-syllable words containing many spelling units. Because the number of spelling units covaried with the number of syllables in this experiment, two additional experiments were designed to separate the effects of these two units of analysis on feature integration. Experiment 2 compared conjunction errors in one-syllable words and two-syllable words that contained the same number of spelling units (e.g., P/AI/NT vs. A/GR/EE). Experiment 3 compared conjunction errors in words containing 
two and three spelling units with the number of syllables held constant (e.g., FR/EE vs. K/EE/P).

\section{EXPERIMENT 1}

Spoehr and Smith (1973, Experiment 2) found that subjects identified letters more accurately in one-syllable words than in two-syllable words in a whole report task. These results support the claim that syllables may function as higher order units in word perception. To provide more direct evidence for this claim, Spoehr and Smith calculated the probability that a letter was reported correctly given that the letter preceding it was reported in correctly (and vice versa). If syllables serve as multiletter units, letters within a syllable should be more likely to be reported together than letters belonging to different syllables. For example, if subjects are presented with the two-syllable word LOW/ER, they should be more likely to report having seen both the $\mathrm{O}$ and $\mathrm{W}$ than both the $\mathrm{W}$ and $\mathrm{E}$, because the first pair of letters belongs to the same syllabic unit. Only some of Spoehr and Smith's data supported this claim.

To explain the inconsistency of their results, Spoehr and Smith suggested that the higher order units in word perception may be syllable-like units termed vocalic center groups (VCGs), rather than syllables. They defined a VCG as "the minimal pronunciational unit in which most articulatory constraints can be fully specified" (Spoehr \& Smith, 1973, p. 80). VCGs are formed according to parsing rules that are followed in a specific order (Hansen \& Rogers, 1965). When a letter string is shown, consonants (C) and vowels (V) are discriminated from one another and the vowels are marked. Consonants that occur before the first vowel in the letter string are grouped together with that vowel. Consonants that follow the last vowel are grouped together with that vowel. The consonants that occur between the first vowel and the last vowel are parsed in accordance with three rules: (1a) VCV $\rightarrow \mathrm{V}+\mathrm{CV}$, (2a) $\mathrm{VCCV} \rightarrow \mathrm{VC}+\mathrm{CV}$, and (3a) VCCCV $\rightarrow$ VC $+C C V$. Finally, a phonological representation is formed for each VCG. If this representation of the word cannot be located in lexical memory, the letter string is parsed again according to a second set of rules: (1b) VCV $\rightarrow \mathrm{VC}+\mathrm{V}$, (2b) $\mathrm{VCCV} \rightarrow \mathrm{V}+\mathrm{CCV}$, (3b) $\mathrm{VCCCV} \rightarrow \mathrm{V}+\mathrm{CCCV}$.

For the word FAVOR, the parsing procedure would mark $A$ and $O$ as vowels. The letter $F$ would be combined with the letter $A$ to form the unit FA, and R would be combined with $O$ to form the unit OR. Following Rule $1 \mathrm{a}, \mathrm{V}$ would be combined with $\mathrm{OR}$ to form the unit VOR. Parsing would terminate at this point because the phonological representation of the word is appropriate (FA/VOR). For the word COLOR, the parsing procedure would mark the two Os as vowels. $\mathrm{C}$ would be combined with the first $\mathrm{O}$ to form the unit $\mathrm{CO}$, and $\mathrm{R}$ would be combined with the final $O$ to form the unit $O R$. Following Rule 1a, $L$ would be combined with the final OR to form the unit LOR. Parsing would not terminate at this point, however, because the phonological representation of the word is inappropriate (CO/LOR). Thus, the letter string would be parsed again in accordance with Rule $1 \mathrm{~b}$, forming an appropriate representation of the word (COL/OR). Note that the second parsing of COLOR is consistent with syllabic boundaries, whereas the first parsing is not.

Spoehr and Smith (1973) applied the VCG parsing rules to the words used in their Experiment 2. They found that the report accuracy for two-syllable words was influenced by the boundary formed after the first VCG parse, regardless of whether the resulting phonological representation was appropriate. Thus, for both FAVOR and COLOR, the boundary between the second and third letters influenced report accuracy, even though the first-parse boundary for COLOR does not correspond to the syllable boundary. Spoehr and Smith also examined performance for only those words that have appropriate phonological representations after being parsed twice (e.g., COLOR). The second-parse boundaries for these words correspond directly with syllabic boundaries. They found that the boundaries formed by the second parse did not influence report accuracy. From these results, Spoehr and Smith concluded that "the number of VCGs formed on the first parse, rather than the number of syllables, appears to be the best predictor of the number of units that need be analyzed and/or translated, and the number of such units predicts variations in report accuracy" (p. 83).

The purpose of the present experiment was to use conjunction errors to determine whether syllables function as higher order perceptual units. Subjects were required to identify the color of a target letter in one-syllable words and two-syllable words composed of different-colored letters. These words were a subset of the words used by Spoehr and Smith (1973, Experiment 2). If syllables function as multiletter units, then letters and colors should be incorrectly combined more often in the one-syllable words than in the two-syllable words. For example, the letter $\mathrm{R}$ in FORCE is free to miscombine with the colors of the letters on either side of it. The V in FA/VOR, on the other hand, is constrained from miscombining with the colors of the $\mathrm{F}$ and $\mathrm{A}$ because these two letters belong to a different syllablic unit.

The claim that syllables serve as higher order units leads to another prediction. Subjects should be more likely to incorrectly combine colors and letters within a syllable than between syllables (Prinzmetal \& Millis-Wright, 1984). The stimuli used in the present experiment were chosen so that the syllable boundary came after the second letter in half of the two-syllable words (e.g., FA/VOR), and after the third letter in the other half (e.g., LOW/ER). These stimuli will be referred to as $2 / 3$ words and $3 / 2$ words, respectively. The subjects' task was to identify the color of the middle letter in these words. When shown a $2 / 3$ word such as FA/VOR, subjects should be more likely to incorrectly report that the target letter (V) is the color of a letter in the fourth or fifth position (O or R) than the color of a letter in the first or second posi- 
tion ( $\mathrm{F}$ or $\mathrm{A}$ ), because the last two letters belong to the same syllabic unit as the target letter. On the other hand, when shown a $3 / 2$ word such as LOW/ER, subjects should be more likely to incorrectly report that the target letter is the color of a letter in one of the first two positions ( $\mathrm{L}$ or $\mathrm{O}$ ) than the color of a letter in one of the last two positions ( $E$ or $R$ ), because the first two letters belong to the same syllable as the target.

The pattern of conjunction errors within two-syllable words was also used to test Spoehr and Smith's (1973) claim that VCGs rather than syllables serve as the primary units of analysis in word processing. In the $2 / 3$ words, syllable boundaries and VCG boundaries coincided directly. However, the $3 / 2$ words were chosen so that syllable boundaries and VCG boundaries did not coincide. According to VCG rules, the $3 / 2$ words should be parsed initially in the same way as the $2 / 3$ words (i.e., between the second and third letters). Thus, if VCGs serve as the primary units of analysis in word processing, then the pattern of conjunction errors within $2 / 3$ words and $3 / 2$ words should not differ.

\section{Method}

Subjects. Eleven New College undergraduate students with normal or corrected-to-normal vision served as subjects. The subjects had no known deficiencies in color vision.

Materials and Apparatus. The stimulus set consisted of six onesyllable words (FORCE, LARGE, PAINT, LEARN, COUNT, and HEARD) and six two-syllable words (FAVOR, LABOR, PAPER, LOWER, COLOR, and HONOR). Each of the words was five letters in length. In half of the two-syllable words the syllable boundary occurred after the second letter (e.g., FA/VOR), while in the other half the syllable break came after the third letter (e.g., LOW/ER). Each two-syllable word matched a one-syllable word in frequency (Thorndike \& Lorge, 1944) and began with the same first letter.

The colors of the letters used in each display were selected from the set red, green, and purple. In all of the displays, four of the letters were the same color, whereas one letter was colored differently. The different-colored letter occurred in each letter position equally often. For each word, the letters were presented in all $\mathbf{3 0}$ possible sequences of colors. Thus, the stimuli consisted of 180 one-syllable word displays and 180 two-syllable word displays. Each display was shown twice.

The stimuli were constructed by assembling preprinted colored letters into words and pasting each word onto a separate $91 / 2 \times$ $53 / 4$ in. index card. Each word was placed randomly in one of the four corners of the card. The closest edges of the corners were approximately $.45^{\circ}$ of visual angle in vertical distance and $.09^{\circ}$ in horizontal distance away from the center of the card. The stimuli were presented via a Scientific Prototype Model GB tachistoscope at a viewing distance of $102 \mathrm{~cm}$. Each five-letter stimulus subtended a visual angle of $2.51^{\circ}$ horizontally and $.54^{\circ}$ vertically. The luminance of the stimulus field was set at approximately $7.5 \mathrm{fc}$. Every stimulus presentation was preceded and followed by a fixation field that matched the stimulus field in luminance.

Procedure. Each subject was told that words composed of five colored letters would be presented briefly through the tachistoscope. The experimenter identified the colors of the stimulus letters, and told the subject that in all of the displays four of the letters would be the same color, whereas one letter would be colored differently. The subject's task was to verbally identify the color of the letter appearing in the middle (third) position. Thus, for example, if the color sequence of the letters in the word was red, red, red, green, red, a correct response would be for the subject to identify the middle letter as "red." The subject was required to guess the color whenever he or she was uncertain. The subject was instructed to gaze at a fixation point before each stimulus presentation. It was explained that each word would appear randomly in one of the four corners of the stimulus field.

The subject was initially given several practice trials to become familiar with the experimental task. The data from these practice trials were used to determine the exposure duration at which a color not represented in the display would be incorrectly reported 5\% of the time. During the practice trials, the subject was told whether his or her responses were correct or incorrect. Each subject completed the practice trials and 720 experimental trials in one 2-h session. The word displays were presented in five blocks of 72 cards each. Each block consisted of 36 one-syllable words and 36 twosyllable words presented in mixed sequence. Each block of cards was presented twice.

The exposure duration was set separately for each block of trials. If the subject incorrectly reported that the target was a color not presented in the display more than $5 \%$ of the time for a particular block of trials, the exposure duration was increased by $5 \mathrm{msec}$ for the next block. If these errors occurred less than $5 \%$ of the time, however, the exposure duration was reduced by $5 \mathrm{msec}$. Otherwise, the exposure duration was not changed between blocks of trials. The exposure durations used in the experimental trials ranged from 10 to $80 \mathrm{msec}$, with a mean exposure duration of $36.82 \mathrm{msec}$.

\section{Results and Discussion}

Subjects misidentified the target color on 1,180 of the 7,920 experimental trials $(14.90 \%)$. The frequency with which subjects made these color identification errors was used to estimate the frequency of feature and conjunction errors. The color identification errors were classified into two types of errors. One type of error occurred when subjects reported that the target letter was a color that was not present in the display (off-error). A second type of error occurred when subjects responded with a color that was present in the display, but was not the color of the target letter (on-error). An off-error may represent only a feature error because the color is not present in the display to be incorrectly combined with the target letter. An on-error, on the other hand, may represent either a feature error or a conjunction error. It represents a feature error when subjects fail to extract the target color and incorrectly guess a color in the display. It represents a conjunction error when letters and colors are correctly extracted but incorrectly combined.

The frequency with which subjects made on-errors was used as a direct measure of conjunction errors. These data were submitted to analyses of variance with number of syllables as a within-subjects factor. Following Clark (1973), separate analyses were conducted with either subjects or words treated as the random factor. The analyses revealed that significantly more on-errors occurred for one-syllable words than for two-syllable words when subjects was treated as the random factor $\left[F_{1}(1,10)=11.42\right.$, $p<.011$, when words was treated as the random factor $\left[F_{2}(1,10)=18.66, p<.001\right]$, and when both subjects and words were treated as random $\left[\min F^{\prime}(1,19)=7.08\right.$, $p<.025 ; M S e=128.04]$. The mean frequency of onerrors was 45.5 and 33.7 for one- and two-syllable words, respectively. 
The frequency with which subjects made off-errors was used as a direct measure of feature errors. Although offerrors represent only a fraction of the total number of feature errors, it was assumed that this proportion was the same for each stimulus type. The analyses indicated that the frequency of off-errors varied with number of syllables when subjects was treated as the random factor $\left[F_{1}(1,10)=5.20, p<.05\right]$ and when words was treated as random $\left[F_{2}(1,10)=6.20, p<.05\right]$, but not when both subjects and words were random $\left[\min F^{\prime}(1,20)=2.83\right.$; $M S e=7.75$ ]. The mean frequency of off-errors was 12.5 and $\mathbf{1 5 . 5}$ for one- and two-syllable words, respectively.

The fact that $F_{1}$ was significant indicates that the effect of number of syllables on off-errors would be replicated if a new sample of 11 subjects were given the same set of words. The significant $F_{2}$ ratio indicates that the effect would also be replicated if the same 11 subjects were shown a new sample of words. A nonsignificant $F^{\prime}$, however, would indicate that the effect would not be replicated if both new subjects and new words were used. Thus, it could be concluded that number of syllables does not influence feature errors. However, in this research, $\min F^{\prime}$ was used as a conservative estimate of $F^{\prime}$. Thus, although $\min F^{\prime}$ was not significant, it is possible that it was "hiding" a significant effect. (Experiment 2 tested this possibility by determining whether feature errors increased with number of syllables when a new set of subjects and words was employed.)

On-errors represent both feature errors and conjunction errors. If it is assumed that fewer off-errors occurred for one-syllable words than for two-syllable words, the fact that the opposite pattern of results was obtained for on-errors suggests that the on-error pattern was due to conjunction errors, rather than to feature errors. If it is assumed that off-errors did not vary with number of syllables, the difference in on-errors should still reflect only a difference in conjunction errors. Thus, either interpretation of the off-error data suggests that subjects were more likely to miscombine colors and letters in onesyllable words than in two-syllable words. These results are consistent with the claim that syllables serve as units of analysis in word processing.

A more direct test of this claim is to determine whether subjects were more likely to miscombine colors and letters within a syllabic unit than between syllables. To test this claim, only trials in which the different-colored letter appeared in one of the first two or one of the last two positions were considered. When the different-colored letter appeared in the middle position and the subject made a conjunction error, it is impossible to determine whether the incorrect color was taken from within or from outside the syllable. For example, if the sequence of colors was red, red, green, red, red, and the subject reported that the target letter was red, it is impossible to determine whether the target letter was miscombined with a nontarget color to the right or to the left of the target letter.

In 2/3 words, the syllable boundary occurs after the second letter (e.g., FA/VOR). Thus, subjects should make more conjunction errors when the different-colored letter appears in the fourth or fifth position (e.g., O or R) than when it occurs in the first or second position (e.g., F or A), because the last two letters belong to the same syllabic unit as the target letter. If the number of conjunction errors that occur when the different-colored letter appears in one of the last two positions is subtracted from the number of conjunction errors for the first two positions, the difference score should be negative.

In $3 / 2$ words, the syllable break comes after the third letter (e.g., LOW/ER). Thus, more conjunction errors should occur when the different-colored letter appears in one of the first two letter positions than when it appears in one of the last two positions. This pattern of errors would produce a positive difference score. Finally, when presented with one-syllable words, subjects should be equally likely to make conjunction errors when the different-colored letter is in one of the first two positions and when it is in one of the last two positions, because all of the letters are in the same syllabic unit. Thus, the difference score should be equal to zero. The overall prediction, then, is that if syllables serve as higher order units, difference scores should be greater for $3 / 2$ words than for one-syllable words, and greater for one-syllable words than for $2 / 3$ words.

On the other hand, if VCGs are the primary units of analysis in words, difference scores for $2 / 3$ words and $3 / 2$ words should be the same. For both types of words, the VCG boundary occurs between the second and third letters. Thus, the difference scores for both types of words should be negative. The overall VCG prediction, then, is that the difference scores for $2 / 3$ words and $3 / 2$ words should not vary, and that these scores should be less than the difference scores for one-syllable words.

The number of on-errors that occurred when the different-colored letter was in one of the last two positions was subtracted from the number of on-errors that occurred when the different-colored letter was in one of the first two positions for each stimulus type. The average difference scores for $2 / 3$ words, $3 / 2$ words, and onesyllable words were $-8.73,7.82$, and 0.64 , respectively. The analyses of variance revealed that on-error difference scores varied significantly with patterns of syllables when subjects was treated as the random factor $\left[F_{1}(2,20)=\right.$ $17.80, p<.001]$, when words was treated as random $\left[F_{2}(2,15)=43.07, p<.001\right]$, and when both subjects and words were random $\left[\min F^{\prime}(2,33)=12.59\right.$, $p<.001, M S e=126.2$ ]. A planned comparison (Lindman, 1974) indicated that the on-error difference scores for $3 / 2$ words were significantly greater than the on-error difference scores for one-syllable words $\left[F_{1}(1,20)=\right.$ $39.99, p<.001 ; F_{2}(1,15)=96.77, p<.001$; $\left.\min F^{\prime}(1,33)=28.30, p<.001\right]$. The comparison also showed that the on-error difference scores for one-syllable words were greater than for $2 / 3$ words $\left[F_{1}(1,20)=68.11\right.$, $p<.001 ; F_{2}(1,15)=164.81, p<.001 ; \min F^{\prime}(1,33)$ $=48.19, p<.001]$. Finally, a $t$ test showed that onerror difference scores for one-syllable words did not 
differ significantly from zero $[t(20)=0.30]$. These results are therefore consistent with the claim that syllables, rather than VCGs, serve as the units of analysis in words.

Difference scores were also calculated for off-errors. The average off-error difference scores for $2 / 3$ words, $3 / 2$ words, and one-syllable words were $0.55,-0.18$, and 0.27 , respectively. As shown by the $t$ tests, these scores did not differ significantly from zero $[t(20)=1.03, t(20)$ $=0.60$, and $t(20)=0.73$, respectively]. These results indicate that the target letter was equally easy to perceive whether the different-colored letter occurred in one of the first two or in one of the last two nontarget positions. Thus, taken together, the results of the on-error and offerror difference scores analyses provide strong evidence that syllables function as higher order units in word perception.

\section{EXPERIMENT 2}

The finding in Experiment 1 that more conjunction errors occurred in one-syllable words than in two-syllable words is consistent with the claim that spelling units may function as higher order units of analysis. The purpose of Experiment 2 was to determine whether syllables influence conjunction errors when the number of spelling units is held constant. Gibson (1965) defined a spelling unit as a "cluster of graphemes in a given linguistic environment which has an invariant pronunciation according to the rules of English" (p. 1071). When GL appears at the beginning of a letter string, for example, the $G$ and $\mathrm{L}$ are always pronounced together as a unit. When UR occurs between clusters of consonants, the $U$ and $R$ are always pronounced together as a unit. And when CK occurs at the end of a string, the $\mathrm{C}$ and $\mathrm{K}$ always form a pronounceable unit. Thus, the pseudoword GLURCK consists of three spelling units (GL/UR/CK). GL is pronounced "gluh,"' UR is pronounced "er," and CK is pronounced "kuh." When the order of the two consonant clusters is switched, however, the resulting letter string contains five spelling patterns $(C / K / U R / G / L)$. UR remains a spelling pattern because it remains between two consonant clusters. CK and GL are not spelling patterns, however, because these pairs of letters are in inappropriate positions in the letter string and cannot be pronounced.

The number of spelling units increased with the number of syllables in some of the words that were used in Experiment 1. For example, the one-syllable words PAINT and COUNT contain three spelling units, whereas the two-syllable words PAPER and COLOR contain four spelling units. Thus, it is possible that more conjunction errors occurred in the one-syllable words than in the twosyllable words because the one-syllable words contained fewer spelling units. For this reason, Experiments 2 and 3 were designed to separate the effects of syllables and spelling units on feature integration.

The purpose of Experiment 2 was to compare conjunction errors for one- and two-syllable words that contained the same number of spelling units. Because it was difficult to find stimulus words to use in this experiment, syllable boundaries were not manipulated systematically. Thus, the data analyses did not compare the frequency of conjunction errors within and between syllables. Only the total numbers of conjunction errors for one- and two-syllable words were compared. If syllables serve as units of analysis in word perception, the results of this experiment should replicate the finding that more conjunction errors occur in one-syllable words than in two-syllable words. However, if only spelling units function as higher order perceptual units, the frequency of conjunction errors should not vary for the two types of words. A second reason for conducting Experiment 2 was to determine whether number of syllables affects feature errors when a new set of subjects and a new set of words are employed.

\section{Method}

Subjects. Fourteen New College undergraduate students who had not participated in Experiment 1 served as subjects.

Procedure. The procedure used in Experiment 2 was identical to that used in Experiment 1, with the following modifications. The stimulus set consisted of six one-syllable words and six two-syllable words that contained three spelling units. Each one-syllable word was matched to a two-syllable word for frequency and pattern of spelling units. Whenever it was not possible to match for frequency perfectly, the two-syllable word had the higher frequency count. Because conjunction errors increase with word frequency (Millis, 1986), the finding that more conjunction errors occur in one-syllable words than in two-syllable words could not be attributed to different word frequencies. The word frequencies were taken from Kucera and Francis's (1967) Computational Analysis of Present-Day American English. The stimulus strings and frequency counts are listed in Appendix A. The exposure durations used in the experimental trials ranged from 5 to $35 \mathrm{msec}$, with a mean exposure duration of $14.07 \mathrm{msec}$.

\section{Results and Discussion}

Subjects misidentified the target color on 2,094 of the 10,080 experimental trials $(20.77 \%)$. Subjects made significantly more on-errors when presented with onesyllable words than when presented with two-syllable words $\left[F_{1}(1,13)=5.89, p<.05 ; F_{2}(1,10)=24.60\right.$, $p<.001 ; \min F^{\prime}(1,19)=4.75, p<.05 ; M S \mathrm{e}=$ 54.86]. The mean frequency of on-errors was 59.1 and 52.3 for one- and two-syllable words, respectively. The frequency of off-errors did not vary with number of syllables when subjects was treated as the random factor $\left[F_{1}(1,13)<1.0\right]$ or when words was treated as the random factor $\left[F_{2}(1,10)<1.0 ; M S \mathrm{e}=1.52\right]$. The mean frequency of off-errors was 19.6 and 18.5 for one- and two-syllable words, respectively.

The off-error results indicate that subjects were able to perceive colors equally well in all of the displays. These results also show that the significant effects obtained in Experiment 1 were not replicated with a new set of subjects and a new set of words. Thus, it can be concluded that number of syllables does not affect feature errors. The on-error data, taken together with the off-error data, suggest that subjects were more likely to miscombine colors and letters in one-syllable words than in two- 
syllable words. These results, therefore, indicate that syllables function as higher order units in word perception.

\section{EXPERIMENT 3}

The results of Experiment 2 do not rule out the possibility that spelling units function as multiletter units, because the number of these units was held constant. Thus, a third experiment was designed to determine whether the number of spelling units affects feature integration when the number of syllables is controlled. In this experiment, subjects were shown monosyllabic words composed of two or three spelling units. If spelling units function as higher order units in word perception, more conjunction errors should occur in words containing two spelling units than in words containing three units. In addition, more conjunction errors should occur within a spelling unit than between spelling units. If, for example, subjects are required to identify the color of the letter $\mathrm{L}$ in the word GLAD, they should be more likely to incorrectly report the color of the $G$ than of the $A$, since $G$ and $L$ are part of the same spelling unit. On the other hand, if syllables are the only units of analysis in word perception, the total number of conjunction errors should not differ for words with two spelling units and words with three spelling units. Also, the pattern of conjunction errors within words should not be influenced by spelling unit boundaries because all of the words are monosyllabic.

\section{Method}

Subjects. Twelve New College undergraduates who had not participated in Experiments 1 or 2 served as subjects.

Procedure. The procedure was identical to that of the previous experiments, with the following modifications. The stimulus set consisted of 15 words composed of two spelling units and 15 words containing three spelling units. All of the two-spelling-unit words followed the spelling pattern $2 / 2$ (e.g., EA/ST). Five of the threespelling-unit words followed the spelling pattern 1/1/2 (e.g., $\mathrm{K} / \mathrm{E} / \mathrm{PT}$ ), five followed the pattern $1 / 2 / 1$ (e.g., $\mathrm{K} / \mathrm{EE} / \mathrm{P}$ ), and five followed the pattern 2/1/1 (e.g., DR/O/P). All of the words were monosyllabic and were four letters in length. Each two-spellingunit word was matched to a three-spelling-unit word for frequency (Kucera \& Francis, 1967). The stimulus strings and frequency counts are listed in Appendix B.

The colors of the letters used in each display were selected from the set pink, green, and blue. In all of the displays, three of the letters were the same color, and one letter was colored differently. The different-colored letter occurred in each letter position equally often. For each word, the letters were presented in all 24 possible sequences of colors. Thus, the stimuli consisted of 360 two-spellingunit word displays and 360 three-spelling-unit word displays. Each display was shown once. Each four-letter stimulus subtended a visual angle of $2.06^{\circ}$ horizontally

Before each trial began, the experimenter said aloud the number 2 or the number 3 . This number represented the second or third letter position in the word. The subject's task was to verbally identify the color of the letter appearing in that position. Half of the displays for each type of word (i.e., $2 / 2,1 / 1 / 2,1 / 2 / 1$, and $2 / 1 / 1$ ) were preceded by the number 2 , and half were preceded by the number 3 .

Each subject completed the practice trials and 720 experimental trials in one $2-\mathrm{h}$ session. The word displays were presented in 10 blocks of 72 cards each. Each block consisted of 36 two-spellingunit words and 36 three-spelling-unit words presented in mixed sequence. The exposure durations used in the experimental trials ranged from 5 to $100 \mathrm{msec}$, with a mean exposure duration of $38.60 \mathrm{msec}$.

\section{Results and Discussion}

Subjects misidentified the target color on 1,420 of the 8,640 experimental trials $(16.44 \%)$. Subjects made significantly more on-errors when presented with twospelling-unit words than when presented with threespelling-unit words $\left[F_{1}(1,11)=7.37, p<.025 ; F_{2}(1,28)\right.$ $=70.03, p<.001 ; \min F^{\prime}(1,13)=6.67, p<.025$; $M S e=46.22]$. The mean frequency of on-errors was 55.4 and 44.7 for two-spelling-unit words and three-spellingunit words, respectively. The frequency of off-errors did not vary with number of spelling units $\left[F_{1}(1,11)<1.0\right.$; $\left.F_{2}(1,28)<1.0 ; M S e=0.22\right]$. The mean frequency of off-errors was 8.8 and 9.5 for two-spelling-unit words and three-spelling-unit words, respectively. ${ }^{1}$ The off-error results suggest that subjects were able to perceive colors equally well in all of the displays. The on-error data, taken together with the off-error data, suggest that subjects were more likely to miscombine colors and letters in twospelling-unit words than in three-spelling-unit words. These results, therefore, support the claim that spelling units function as units of analysis in word processing.

A more direct test of this claim is to determine whether subjects were more likely to miscombine colors and letters within a spelling unit than between spelling units. To test this claim, when the target letter was in the second position, only data from trials in which the differentcolored letter appeared in the first or third position were analyzed. When the target letter was in the third position, only trials in which the different-colored letter appeared in the second or fourth position were considered.

The analyses compared errors in the four types of words: $2 / 2$ words (e.g., EA/ST), 1/1/2 words (e.g., $\mathrm{K} / \mathrm{E} / \mathrm{PT}$ ), $2 / 1 / 1$ words (e.g., DR/O/P), and $1 / 2 / 1$ words (e.g., K/EE/P). When the target was the second letter, difference scores were obtained by subtracting the number of errors that occurred when the different-colored letter appeared in the third position from the number of errors made when it appeared in the first position. If spelling units function as multiletter units, these scores should be positive for the $2 / 2$ and $2 / 1 / 1$ words, because the first letter belongs to the same spelling unit as the target letter. The difference scores should be negative for the $1 / 2 / 1$ words, however, because the third letter belongs to the same spelling unit as the target letter. Finally, the difference scores should be zero for $1 / 1 / 2$ words, since neither the first nor the third letter is in the same spelling unit as the target.

When the target letter was in the second position, the average on-error difference scores were $7.25,0.75,7.25$, and -5.25 for $2 / 2$ words, $1 / 1 / 2$ words, $2 / 1 / 1$ words, and $1 / 2 / 1$ words, respectively. The analyses of variance revealed that on-error difference scores varied significantly 
with the pattern of spelling units $\left[F_{1}(3,33)=16.88\right.$, $p<.001 ; F_{2}(3,56)=54.47, p<.001 ; \min F^{\prime}(3,54)=$ $12.89, p<.001 ; M S e=28.87]$. A planned comparison indicated that the on-error difference scores for $2 / 2$ words and $2 / 1 / 1$ words did not differ significantly $\left[F_{1}(1,33)<1.0 ; F_{2}(1,56)<1.0\right]$. The mean on-error difference score averaged across these two types of spelling patterns was significantly greater than the on-error difference scores for $1 / 1 / 2$ words $\left[F_{1}(1,33)=197.66\right.$, $p<.001 ; F_{2}(1,56)=637.74, p<.001 ; \min F^{\prime}(1,54)$ $=150.89, p<.001]$. The comparison also showed that the difference scores were greater for $1 / 1 / 2$ words than for $1 / 2 / 1$ words $\left[F_{1}(1,33)=126.32, p<.001 ; F_{2}(1,56)\right.$ $\left.=407.55, p<.001 ; \min F^{\prime}(1,54)=96.43, p<.001\right]$. Finally, a $t$ test showed that the on-error difference scores for $1 / 1 / 2$ words did not differ significantly from zero $[t(33)=0.06]$. These results are consistent with the predictions.

When the target was the third letter, difference scores were obtained by subtracting the number of errors that occurred when the different-colored letter appeared in the fourth position from the number of errors made when it appeared in the second position. These scores should be positive for the $1 / 2 / 1$ words, because the second letter belongs to the same spelling unit as the target letter. The difference scores should be negative for the $2 / 2$ and $1 / 1 / 2$ words, because the fourth letter belongs to the same spelling unit as the target letter. Finally, the difference scores should be zero for $2 / 1 / 1$ words, because neither the second nor the fourth letter is in the same spelling unit as the target.

When the target letter was in the third position, the average on-error difference scores were $-5.00,-5.25,1.50$, and 7.75 for $2 / 2$ words, $1 / 1 / 2$ words, $2 / 1 / 1$ words, and $1 / 2 / 1$ words, respectively. The analyses of variance revealed that on-error difference scores varied significantly with pattern of spelling units $\left[F_{1}(3,33)=18.53\right.$, $p<.001 ; F_{2}(3,56)=48.52, p<.001 ; \min F^{\prime}(3,58)=$ $13.41, p<.001 ; M S \mathrm{e}=30.57$ ]. A planned comparison indicated that the on-error difference scores for $2 / 2$ words and $1 / 1 / 2$ words did not differ significantly $\left[F_{1}(1,33)<1.0 ; F_{2}(1,56)<1.0\right]$. The mean difference score averaged across these two types of spelling patterns was significantly less than the difference scores for $2 / 1 / 1$ words $\left[F_{1}(1,33)=212.8, p<.001 ; F_{2}(1,56)=557.34\right.$, $\left.p<.001 ; \min F^{\prime}(1,58)=154.0, p<.001\right]$. The comparison also showed that difference scores for $2 / 1 / 1$ words were significantly less than difference scores for $1 / 2 / 1$ words $\left[F_{1}(1,33)=142.05, p<.001 ; F_{2}(1,56)=\right.$ $\left.372.02, p<.001 ; \min F^{\prime}(1,58)=102.8, p<.001\right]$. Finally, a $t$ test showed that the on-error difference scores for $2 / 1 / 1$ words did not differ significantly from zero $[t(33)=0.95]$. These results are consistent with the predictions.

Difference scores were also calculated for off-errors. When the target letter was in the second position, the average difference scores were $0.67,0.50,0.50$, and 1.00 for $2 / 2$ words, $1 / 1 / 2$ words, $2 / 1 / 1$ words, and $1 / 2 / 1$ words, respectively. As shown by $t$ tests, these scores did not differ significantly from zero $[t(33)=1.26, t(33)=1.09$, $t(33)=1.09$, and $t(33)=1.54$, respectively]. These results indicate that the target letter was equally easy to perceive whether the different-colored letter occurred in the first or third nontarget position.

When the target letter was in the third position, the average off-error difference scores were $0.50,1.00,0.50$, and 0.25 for $2 / 2$ words, $1 / 1 / 2$ words, $2 / 1 / 1$ words, and $1 / 2 / 1$ words, respectively. As shown by $t$ tests, these scores did not differ significantly from zero $[t(33)=1.34, t(33)=$ $1.89, t(33)=1.34$, and $t(33)=0.95$, respectively]. These results indicate that the target letter was equally easy to perceive whether the different-colored letter occurred in the second or fourth nontarget position. Thus, taken together, the results of the on-error and off-error difference scores analyses provide strong evidence that spelling patterns serve as higher order units of analysis in word processing.

\section{GENERAL DISCUSSION}

The results of the present research suggest that both syllables and spelling units function as units of analysis in word perception. In Experiment 1, subjects incorrectly combined letters and colors more often in one-syllable words than in two-syllable words. However, this finding could not be used to distinguish between spelling patterns and syllables, because these two units covaried in the words. Thus, two additional experiments were designed to separate the effects of syllabic and spelling patterns on feature integration. Experiment 2 demonstrated that subjects made more conjunction errors in one-syllable words than in two-syllable words when the number of spelling patterns was controlled. Experiment 3 showed that conjunction errors decreased as spelling units increased when the number of syllables was held constant. In addition, Experiments 1 and 3 showed that more conjunction errors occurred within syllabic and spelling units than between these units.

Several other experimental paradigms have been used to test the claim that spelling patterns and syllables serve as perceptual units. The present experiments hold several advantages over this previous research, however. For example, much research has attempted to show that spelling patterns facilitate perceptual accuracy and reaction time. Gibson et al. (1962) found that subjects identified letters more accurately in pseudowords such as GLURCK than in orthographically irregular nonwords such as CKURGL. The results of this type of study cannot be used to argue that only spelling units serve as multiletter units, however, because orthographic regularities are confounded with phonological factors. Thus, one advantage of the present experiments is that the effects of orthographic and phonological factors were separated.

Other experiments have attempted to demonstrate that orthographic regularity affects performance when pronounceability is controlled. Baron and Thurston 
(1973), for example, found that chemists were able to compare chemical formulas more quickly when the formulas were "spelled" correctly (e.g., $\mathrm{NaCl}$ ) than when the anion preceded the cation (e.g., ClNa). Baron (1974) showed that subjects were able to report the identity of a consonant pair more accurately when the order of the consonants was constrained (e.g., KV, KZ) than when the order was not constrained (e.g., HG, HJ, GH, JH). Spoehr and Smith (1975) found that nonwords composed entirely of consonants were perceived more accurately when they contained two spelling units (e.g., BL/ST) than when they contained four units (e.g., L/S/T/B).

The major problem with all of this research is that artificial stimulus materials were used to separate the effects of orthographic and phonological factors. It is not clear that either arbitrary order constraints or rules for writing chemical formulas function in the same way as spelling rules. And, although the letter strings used by Spoehr and Smith (1975) contained spelling patterns that actually occur in written English, only an orthographic, and not a phonological, definition of spelling patterns was used to create these stimulus materials. This manipulation is artificial, because many of the spelling rules in English are governed by phonological constraints. That is, some groups of letters are not permitted in written words because they are unpronounceable. For example, $G$ and $\mathrm{K}$ may not occur together because the phonemes corresponding to these two letters cannot be pronounced together. Gibson (1965) defined spelling patterns in terms of both orthographic and phonological rules. Spoehr and Smith (1975) admitted that the "separation of the orthographic and phonemic determinants of spelling patterns may be quite artificial" (p. 23). However, they attempted to justify this separation by citing Gibson, Shurcliff, and Yonas's (1970) finding that a word superiority effect was obtained with deaf subjects. Unfortunately, although Gibson et al. presumed that their subjects had no knowledge of pronunciation rules, no evidence was provided to support this assumption. Thus, the use of artificial stimuli remains a problem in Spoehr and Smith's research. Their research does not show that spelling patterns facilitate the perception of letters in words. Thus, a second advantage of the present research is that it shows that spelling patterns affect performance independently of phonological factors (i.e., syllables) when words are used as stimuli.

Miura (1978) also separated the effects of orthographic structure and pronounceability using more natural stimulus materials. Subjects were presented with words and nonwords composed of Hiragana letters. Each Hiragana letter has an invariant one-syllable pronunciation, and thus generates a single vocalic center group. Because strings of Hiragana letters were used, the words and nonwords in this experiment contained the same number of VCGs. The results showed that words were recognized more accurately than either nonwords or single Hiragana VCGs. Miura argues that only familiarity with spelling rules could account for this demonstration of the word superiority effect. One problem with this interpretation, however, is that there is no direct evidence in Miura's results that spelling patterns function as higher order perceptual units. The existence of these units can only be inferred from the finding that perceptual accuracy increases as orthographic regularity increases. Thus, a third strength of the present research is that it provides direct evidence for spelling units by showing that these units are reflected in the pattern of conjunction errors within words.

A fourth advantage of the present experiments is that both spelling patterns and syllables are shown to function as multiletter units in the same experimental task. Although Miura found indirect evidence for spelling units, his experiment cannot be used to determine whether VCGs serve as perceptual units, because these units were held constant in the stimulus materials. And, although Spoehr and Smith (1973) found support for the existence of VCG units, they did not examine the effect of spelling patterns on perceptual accuracy.

In a more recent set of experiments, however, Spoehr and Smith (1975) found evidence for both spelling and VCG units, using the same experimental task. As indicated earlier, they found that perceptual accuracy decreased as number of spelling patterns increased in nonwords composed entirely of consonants. In addition, they found that these consonant-nonwords were perceived less accurately than pronounceable pseudowords even though the pseudowords contained a greater number of spelling patterns (e.g., BL/O/ST vs. BL/ST). Spoehr and Smith argued that if only spelling patterns function as higher order units, perceptual accuracy should have been poorer for the pseudowords. Thus, the latter results suggest that VCGs may also function as higher order perceptual units.

Spoehr and Smith (1975) offered a phonological recoding explanation to account for their results. They proposed that a letter string is first parsed into VCGs. These units are then decomposed into spelling patterns in order that the letter string may be converted into a phonological code. According to this explanation, spelling patterns facilitate the recoding process, because these units can be matched directly to speech sounds. This account suggests that VCGs are the primary units of analysis in word perception, whereas spelling patterns play a major role during recoding. In support of this explanation, Spoehr and Smith found that pronounceable pseudowords (e.g., ROST) are perceived more accurately than unpronounceable nonwords that contain a vowel (e.g., RNOT), and that vowel-nonwords are perceived more accurately than nonwords that contain only consonants (e.g., RNST).

There are several problems with Spoehr and Smith's (1975) research. First, because artificial stimulus materials were used, the results cannot be used to argue that spelling patterns and VCGs are processed in words. Second, only indirect evidence was provided for the existence of spelling units and VCGs. Third, the phonological recoding explanation seems somewhat unlikely, because it postulates that letters are grouped together into syllabic units only to be broken down again into smaller spelling patterns and individual letters. Spoehr and Smith ac- 
knowledged this last problem, and proposed that an alternative explanation for their results is that letter strings are first matched to representations for VCGs, then to spelling units, and finally to letters in visual memory. There is evidence, however, that VCGs do not necessarily serve as the primary units of analysis even in the restricted set of artificial stimuli used by Spoehr and Smith. Prinzmetal and Millis-Wright (1984) found that conjunction errors did not differ for nonwords containing a vowel and nonwords containing only consonants. Thus, it is not clear that it is necessary to develop a model of word perception to accommodate the primacy of VCGs. Future research should address the question of why different results are obtained when letter detection accuracy and conjunction errors are used as dependent measures. One possibility is that Prinzmetal and Millis-Wright failed to find an effect of vowels on feature integration because the experimental conditions did not encourage verbal recoding (Spoehr, 1978).

Prinzmetal and Millis-Wright's (1984) finding that conjunction errors did not vary for vowel-nonwords and consonant-nonwords is consistent with the results of the present research, because both sets of experiments fail to show that VCGs influence conjunction errors. One advantage of the present research is that the failure to obtain an effect was demonstrated with words rather than with artificial stimuli. Experiment 1 showed that VCGs influenced the pattern of conjunction errors within words only when these units coincided directly with syllables (i.e., 2/3 words). When the VCG and syllable boundaries did not coincide (i.e., $3 / 2$ words), the pattern of conjunction errors was influenced by syllable boundaries. Thus, this research argues against Spoehr and Smith's (1973) conclusion that VCGs, rather than syllables, function as multiletter units.

Unlike the results of Spoehr and Smith (1975), the results of the present research are not used to argue for the existence of a primary unit of analysis in word perception. Because it is not necessary to postulate that higher order units are processed in a particular order, the present results are consistent with a number of models of word perception (e.g., Estes, 1975; LaBerge \& Samuels, 1974). One problem with these models is that they fail to specify the nature of the multiletter units that occur between the letter and word levels of analysis. The experiments reported here show that syllables (rather than VCGs) and spelling units (defined by both orthographic and phonological rules) serve as these multiletter units.

The results of the present research suggest that the feature integration paradigm may also be used to study the acquisition of reading units in children. According to LaBerge and Samuels (1974), learning to read entails learning to organize information into larger and larger units. First, children learn to organize parts of letters into whole letters. Letters are eventually grouped together into spelling and pronunciation patterns, and these patterns are grouped together into words. Conjunction errors may be compared in words and nonwords to determine the age at which each of these levels of reading acquisition occurs. At the stage when only individual letters are processed in words, conjunction errors should not vary between words and nonwords. When children begin to process words as multiletter units, however, more conjunction errors should occur in the words. The pattern of conjunction errors within words can be used to determine whether these multiletter units are spelling patterns, syllables, whole words, or so forth. Such experiments are currently being conducted. Future research can also use this experimental paradigm with reading-disabled children in order to identify the stages at which difficulties arise.

\section{REFERENCES}

Aderman, D., \& Smith, E. E. (1971). Expectancy as a determinant of functional units in perceptual recognition. Cognitive Psychology, 2, 117-129.

Baron, J. (1974). Facilitation of Perception by spelling constraints. Canadian Journal of Psychology, 28, 37-50.

Baron, J., \& ThUrston, I. (1973). An analysis of the word-superiority effect. Cognitive Psychology, 4, 207-228.

Bjork, E. L., \& Murray, J. T. (1977). On the nature of input channels in visual processing. Psychological Review, 84, 472-484.

Carr, T. H., Davidson, B. J., \& Hawkins, H. L. (1978). Perceptual flexibility in word recognition: Strategies affect orthographic computation but not lexical access. Journal of Experimental Psychology: Human Perception \& Performance, 4, 674-690.

Cattell, J. M. (1886). The time it takes to see and name objects. Mind, 11, 63-65.

Clark, H. H. (1973). The language-as-a-fixed-effect fallacy: A critique of language statistics in psychological research. Journal of Verbal Learning \& Verbal Behavior, 12, 335-359.

Egeth, H., \& Blecker, D. (1971). Differential effects of familiarity on judgments of sameness and difference. Perception \& Psychophysics, 9, 321-326.

ESTES, W. K. (1972). Interactions of signal and background variables in visual processing. Perception \& Psychophysics, 12, 278-286.

Estes, W. K. (1975). Memory, perception, and decision in letter identification. In R. L. Solso (Ed.), Information processing and cognition: The Loyola Symposium. Hillsdale, NJ: Erlbaum.

Grbson, E. J. (1965). Learning to read. Science, 148, 1066-1072.

Gibson, E. J., Bishop, C. H., Schiff, W., \& SMith, J. (1964). Comparison of meaningfulness and pronounceability as grouping principles in the perception and retention of verbal material. Journal of Experimental Psychology, 67, 173-182.

Gibson, E. J., Pick, A. D., Osser, H., Hammond, M. (1962). The role of grapheme-phoneme correspondence in the perception of words. American Joumal of Psychology, 75, 554-570.

Gibson, E. J., ShurclifF, A., \& Yonas, A. (1970). Utilization of spelling patterns by deaf and hearing subjects. In H. Levin \& J. P. Williams (Eds.), Basic studies in reading. New York: Basic Books.

HANSEN, D., \& Rogers, T. S. (1965). An exploration of psycholinguistic units in initial reading. In Proceedings of the Symposium on the Psycholinguistic Nature of the Reading Process. Detroit: Wayne State University.

HermanN, D. J., \& Mclaughlin, J. P. (1973). Language habits and detection in very short-term memory. Perception \& Psychophysics, 14, 483-486.

Kučera, H., \& Francis, W. N. (1967). Computational Analysis of present-day American English. Providence, RI: Brown University Press.

LABerge, D., \& SAmuels, S. J. (1974). Toward a theory of automatic information processing in reading. Cognitive Psychology, 6, 293-323.

Lindman, H. R. (1974). Analysis of variance in complex experimental designs. San Francisco: W. H. Freeman.

Manelis, L. (1974). The effect of meaningfulness in tachistoscopic word perception. Perception \& Psychophysics, 16, 182-192. 
McClelland, J., \& Johnston, J. (1977). The role of familiar units in the perception of words and nonwords. Perception \& Psychophysics, 22, 249-261

MiLLIS, M. (1986). Effects of word frequency and polysemy on visual feature integration. Manuscript submitted for publication.

MiurA, T. (1978). The word superiority effect in a case of Hiragana letter strings. Perception \& Psychophysics, 24, 505-508.

Pillsbury, W. B. (1897). The reading of words: A study in apperception. American Journal of Psychology, 8, 315-393.

Prinzmetal, W. (1981). Principles of feature integration in visual perception. Perception \& Psychophysics, 30, 330-340.

Prinzmetal, W., \& Millis-Wright, M. (1984). Cognitive and linguistic factors affect visual feature integration. Cognitive Psychology, 16, 305-340.

ReICHER, G. M. (1969). Perceptual recognition as a function of meaningfulness of stimulus material. Journal of Experimental Psychology, 81 , 275-280.

RUMELhART, D. E. (1970). A multicomponent theory of the perception of briefly exposed visual displays. Journal of Mathematical Psychology, 7, 191-218.

Shiffrun, R. M., \& Geisler, W. S. (1973). Visual recognition in a theory of information processing. In R. L. Solso (Ed.), Contemporary issues in cognitive psychology: The Loyola Symposium. Washington, DC: V. H. Winston.

SMITH, E. E., Haviland, S. E. (1972). Why words are perceived more accurately than nonwords: Inference vs. unitization. Journal of Experimental Psychology, 92, 59-64.

SPozhr, K. T. (1978). Phonological encoding in visual word recognition. Journal of Verbal Learning \& Verbal Behavior, 17, 127-141.

Spozhr, K. T., Smith, E. E. (1973). The role of syllables in perceptual processing. Cognitive Psychology, 5, 71-89.

SPOEHR, K. T., SMITH, E. E. (1975). The role of orthographic and phonotactic rules in perceiving letter patterns. Journal of Experimental Psychology: Human Perception \& Performance, 104, 21-34.

THORNDIKE, E. L., \& LORGE, I. (1944). The teacher's word book of 30,000 words. New York: Teachers College, Columbia University.

Treisman, A., Gelade, G. (1980). A feature integration theory of attention. Cognitive Psychology, 12, 97-136.

TreismaN, A., \&ChmidT, H. (1982). Ilusory conjunctions in the perception of objects. Cognitive Psychology, 14, 107-141.

Wolforo, G. (1975). Perturbation model for letter identification. Psychological Review, 82, 184-199.

Wolford, G., \& SHUM, K. H. (1980). Evidence for feature perturbations. Perception \& Psychophysics, 27, 409-420.

\section{NOTE}

1. The overall percentage of off-errors for Experiment 3 was $2.5 \%$, whereas the percentages of off-errors for Experiments 1 and 2 were $3.9 \%$ and $5.3 \%$, respectively. The $5 \%$ off-error threshold rule was used to adjust the exposure duration in all of these experiments. However, because the frequency of off-errors decreased dramatically during the ex- perimental trials in Experiment 3, the exposure duration had to be decreased by $5 \mathrm{msec}$ for several blocks in a row before the appropriate off-error level was reached. Thus, the overall level of off-errors was low for this experiment. However, because the off-error and on-error data in Experiment 3 exactly parallel the results of the other two experiments, the low magnitude of off-errors does not affect the general conclusions of this research.

\section{APPENDIX A}

Spelling Patterns and Frequency Counts of the Words Used in Experiment 2

\begin{tabular}{lcclr}
\multicolumn{2}{c}{ One Syllable } & & \multicolumn{2}{c}{ Two Syllables } \\
\cline { 5 - 5 } Word & Frequency & & Word & Frequency \\
\cline { 1 - 2 } f ir st & 1,360 & & o th er & 1,702 \\
b ir ch & 2 & & a sh er & 2 \\
p oa ch & 1 & & e th er & 1 \\
c ou nt & 49 & & a gr ee & 51 \\
sl e pt & 27 & & ea g er & 27 \\
fr ea k & 4 & & sn ow y & 4 \\
(Average) & 240.5 & & (Average) & 297.8 \\
\hline
\end{tabular}

\section{APPENDIX B \\ Spelling Patterns and Frequency Counts of the Words Used in Experiment 3}

\begin{tabular}{lcccr}
\hline \multicolumn{2}{c}{ Two Spelling Units } & & \multicolumn{2}{c}{ Three Spelling Units } \\
\cline { 5 - 5 } Word & Frequency & & Word & Frequency \\
\hline ea st & 183 & & k e pt & 186 \\
cr ew & 36 & & c a sh & 36 \\
tr ay & 18 & & b u nk & 18 \\
gl ue & 8 & d o ck & 8 \\
pl ea & 11 & d a sh & 11 \\
fr ee & 260 & k ee p & 264 \\
tr ue & 231 & t ur n & 233 \\
oa th & 6 & g oa t & 6 \\
pr ay & 12 & l ea f & 12 \\
sh oe & 14 & h ea p & 14 \\
tr ee & 59 & dr o p & 59 \\
dr aw & 56 & sp o t & 57 \\
gl ow & 16 & gr a b & 16 \\
cr ow & 2 & br a g & 2 \\
ch ew & 2 & bl o b & 2 \\
(Average) & 60.93 & (Average) & 61.60 \\
\hline
\end{tabular}

(Manuscript received November 19, 1985; revision accepted for publication May 5, 1986.) 